\title{
The learning curve of laparoscopic liver resection utilising a difficulty score
}

\author{
Arpad Ivanecz ${ }^{1,2}$, Irena Plahuta ${ }^{1}$, Matej Mencinger ${ }^{3,4,5}$, Iztok Perus ${ }^{2,6}$, Tomislav Magdalenic ${ }^{1}$, \\ Spela Turk ${ }^{1}$, Stojan Potrc ${ }^{1,2}$ \\ ${ }^{1}$ Clinical Department of Abdominal and General Surgery, University Medical Centre Maribor, Maribor, Slovenia \\ ${ }^{2}$ Department of Surgery, Faculty of Medicine, University of Maribor, Maribor, Slovenia \\ ${ }^{3}$ Faculty of Civil Engineering, Transportation Engineering and Architecture, University of Maribor, Maribor, Slovenia \\ ${ }^{4}$ Centre of Applied Mathematics and Theoretical Physics, University of Maribor, Maribor, Slovenia \\ ${ }^{5}$ Institute of Mathematics, Physics and Mechanics, Ljubljana, Slovenia \\ ${ }^{6}$ Faculty of Natural Science and Engineering, University of Ljubljana, Ljubljana, Slovenia
}

Radiol Oncol 2022; 56(1): 111-118.

Received 2 June 2021

Accepted 16 July 202

Correspondence to: Assist. Prof. Arpad Ivanecz, M.D., Ph.D., Clinical Department of Abdominal and General Surgery, University Medical Centre Maribor, Ljubljanska ulica 5, 2000 Maribor, Slovenia. E-mail: arpad.ivanecz@ukc-mb.si

Disclosure: No potential conflicts of interest were disclosed.

This is an open access article under the CC BY-NC-ND license (http://creativecommons.org/licenses/by-nc-nd/4.0/).

Background. This study aimed to quantitatively evaluate the learning curve of laparoscopic liver resection (LLR) of a single surgeon.

Patients and methods. A retrospective review of a prospectively maintained database of liver resections was conducted. 171 patients undergoing pure LLRs between April 2008 and April 2021 were analysed. The Halls difficulty score (HDS) for theoretical predictions of intraoperative complications (IOC) during LLR was applied. IOC was defined as blood loss over $775 \mathrm{~mL}$, unintentional damage to the surrounding structures, and conversion to an open approach. Theoretical association between HDS and the predicted probability of IOC was utilised to objectify the shape of the learning curve.

Results. The obtained learning curve has resulted from thirteen years of surgical effort of a single surgeon. It consists of an absolute and a relative part in the mathematical description of the additive function described by the logarithmic function (absolute complexity) and fifth-degree regression curve (relative complexity). The obtained learning curve determines the functional dependency of the learning outcome versus time and indicates several local extreme values (peaks and valleys) in the learning process until proficiency is achieved.

Conclusions. This learning curve indicates an ongoing learning process for LLR. The proposed mathematical model can be applied for any surgical procedure with an existing difficulty score and a known theoretically predicted association between the difficulty score and given outcome (for example, IOC).

Key words: learning curve; difficulty score; laparoscopy; hepatectomy; intraoperative complication

\section{Introduction}

Interest in laparoscopic liver resection (LLR) has grown since the publication of the International Louisville Statement on laparoscopic liver surgery. ${ }^{1}$ Since then, the number of LLRs performed worldwide has increased exponentially. ${ }^{2}$
The laparoscopic approach must not compromise the technical quality of the liver resection. The message from the second Morioka consensus conference in 2014 was the need for a formal structure of education for those interested in performing LLR. ${ }^{3}$ The need for the organisation of LLR was achieved by the establishment of the 
International Laparoscopic Liver Society in $2016 .{ }^{4}$ In Southampton, 2017, the third consensus meeting has produced a set of clinical practice guidelines to direct the speciality's continued safe progression and dissemination. ${ }^{5}$ A few difficulty scoring systems have been proposed to rate the difficulty of LLR, and the need for validating the existing tools before the clinical application has been highlighted. ${ }^{6-9}$ Halls et al. ${ }^{10}$ developed and internally validated a difficulty score estimating the risk of intraoperative complications (IOC) during LLR, which was externally validated by the authors of the present study. ${ }^{11}$

Along with the evolution of LLR, its learning curves (LCs) have received increased attention. ${ }^{12-14}$ The idealised model of the LC has been described, demonstrating continuous result improvement along with experience. ${ }^{15}$ Recently, the LC has been reported to resemble a true model, in which alternating periods of progression and regression occurred until mastery was achieved. ${ }^{16}$

The present study was based on a thirteen-years single-centre experience and was designed to analyse the real LC of LLR. To the best of our knowledge, it is the only study quantitatively presenting the LC of LLR.

\section{Patients and methods}

\section{Patients}

Study subjects were identified from a prospectively maintained database of patients who underwent liver resections at the Department of Abdominal and General Surgery, University Medical Centre Maribor, Slovenia. This institution has been a tertiary referral centre specialised in hepato-pancreato-biliary surgery, where the first LLR was performed in April 2008. The study included all the patients in whom a pure laparoscopic liver procedure was performed (intention-to-treat analysis) until $31^{\text {st }}$ March 2021. For the present study, patients who underwent laparoscopic cyst fenestration, liver biopsies, and radiofrequency ablation were excluded.

Only pure LLR were performed; no hand-assisted or hybrid procedures were used. All patients were operated by the same surgeon (AI). He had expertise in open hepato-pancreatico-biliary and laparoscopic surgery but no experience in LLR before this series. Perioperative definitions were provided elsewhere. ${ }^{11}$ The surgical technique for LLR has been extensively described by others ${ }^{17}$ and performed as reported previously. ${ }^{18-20}$
At the time of the operation all patients had given their written consent that anonymous data can be used for research purposes. Patient records were anonymized and de-identified before analysis. Ethical approval for this study was obtained from the local institutional review board.

\section{Statistical analysis}

IBM SPSS for Windows Version 26.0 (IBM Corp., Armonk, NY, USA) and Wolfram Mathematica for Windows Version 10.4 (Wolfram Research, Inc., Champaign, IL, USA) were used for statistical computations.

Categorical variables were reported as frequency (percentages). Continuous variables were reported as mean and standard deviation when data distribution was normal; otherwise, they were reported as median (minimum-maximum, interquartile range). The chi-square and the paired samples t-test were used. Percentages were listed to one decimal place, and a difference in the $\mathrm{P}$-value of $<0.05$ was considered statistically significant.

\section{Mathematical modelling of the learning curve}

The Halls difficulty score (HDS) $)^{10}$ was applied. Its parameters (neoadjuvant chemotherapy, previous open liver resection, benign or malignant lesion, lesion size, and classification of resection) were captured from the institutional database. Each LLR was retrospectively scored from 0 to 15 .

In the proposed model, IOC was used as a sensible measure of the complexity of the resection. ${ }^{10}$ IOC's key markers were blood loss over $775 \mathrm{~mL}$, unintentional damage to the surrounding structures and conversion to open approach. ${ }^{10}$ The conversion was defined as the requirement for laparotomy at any time of the procedure, except for the extraction of the resected specimen. ${ }^{10}$

$\mathrm{In}^{11}$, the authors searched for functorial dependence between IOC and HDS using the first 128 patients of the observed cohort. The best-fit-dependency was found to be the Weibull cumulative distribution function ${ }^{21}$ of the form

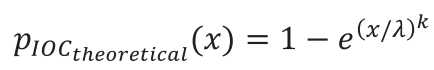

with $\lambda=8.085$ and $k=2.871$. Here $x$ represents the HDS, and $p_{I O C_{\text {theoretical }}}(x)$ represents the predicted probability of IOC occurrence. This functional dependence will be referred as the theoretical probability of $\mathrm{IOC}^{11}$ and is graphically represented in 
Figure 1. This figure is rendered here for the selfsufficiency of this article.

The Weibull curve in Figure 1 is monotonically increasing. Regarding the LC, we assume that a procedure with a higher difficulty score must be graded better than a procedure with a lower difficulty score if the resection is done without IOC. Therefore, the difference between the theoretically predicted probability of IOC and obtained IOC is greater if the difficulty score is higher (if IOC $=0$ ). On the other hand, if IOC was detected (if IOC $=1$ ), the difference between the theoretically predicted probability of IOC and obtained IOC is negative (implying a lower grade for a surgeon) if the difficulty score is low. Thus, the learning outcome is proportional to the share of IOC caused by the surgeon obtained in each of the ten classes.

We wanted to test if the time dependency of HDS is (on average) an ascending function. Therefore, resections were divided into three (time) sequential classes (each consisting of 57 patients), and the number of obtained IOC in each class was counted.

HDS $^{10}$ was used in the analysis of LC. Its dependency was proven to be (on average) an increasing function (Figure 1).

\section{The proposed mathematical model of a learning curve}

The probability (the share of IOC in the time-dependent class) of IOC depends on HDS. The share of IOC in a time-dependent class measures the complexity of resections. Therefore, a novel model for presenting the learning outcome in the case of LLR with existing theoretical dependence between HDS and (the probability of) IOC was introduced.

We assume that the learning outcome consists of two additive components. The first represents the absolute complexity of the resection according to time (which is proportional to effort). The second (additive) component is obtained by comparing the share of IOC to the theoretically predicted (probability of) IOC depending on the HDS of the patient. Components share the same physical units; therefore, the addition is justified. The sum of components results in the learning outcome for any patient and finally in the LC. The first component reflects the absolute complexity of the resections within the same class, while the second one reflects the relative complexity (comparing to the theoretically predicted HDS), which can be interpreted as the surgeon's efficiency.

At this point, we mathematically define the objectives determining the learning outcomes, and

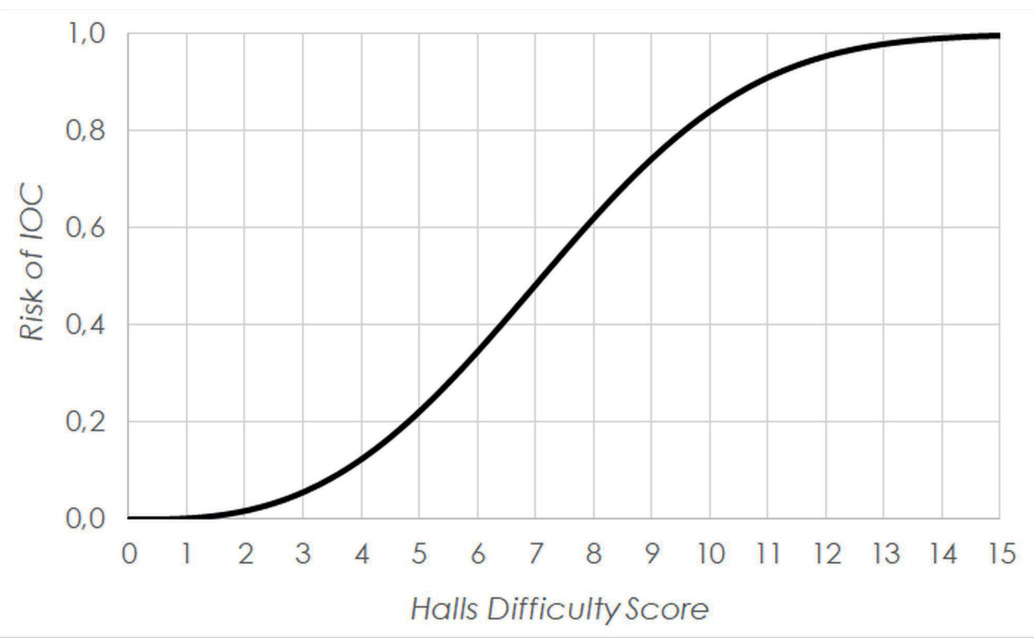

FIGURE 1. The continuous mean risk curve of intraoperative complication (IOC) as a function of the Halls difficulty score: the theoretical probability of intraoperative complication."

consequently, the LC. The cohort of 171 patients is divided into ten sequential classes (the last class contains $17+1$ patient). By $n$, we denote the sequential number of the patient. By $N$, we denote the sequential number of the class (for every class, its cardinality $\# N$ is equal to 17$)$.

Our main assumptions and proposals are the following:

1. Since the resections were listed chronologically, we may assume that the sequential number of the patient corresponds to the effort of the surgeon (the correspondence is monotonically increasing).

2. For every class $N$, the absolute complexity ( $a c$ ) of the tasks in the class is proportional to the ratio of the IOC cases.

$$
\operatorname{ac}(N)=\sum_{n_{i} \in N} p_{I O C_{\text {theoretical }}}\left(n_{i}\right)
$$

The non-smooth dependency $\left(N_{i}, a c\left(N_{i}\right)\right) ; i=1,2, \ldots, 10$ was fitted to smooth logarithmic function $\operatorname{ac}(N)=f(N)$. Additionally, it was modified to absolute complexity for each sequential patient $(A C)$

$A C(n)=f\left(\frac{n+16}{17}\right)$.

3. For every class $N$, the relative complexity $(r c)$ or efficiency of the surgeon is proportional to the sum of differences between the theoretically predicted probabilities of IOC and the obtained probabilities of IOC

$$
r c(N)=\sum_{n_{i} \in N} p_{I O C_{\text {theoretical }}}\left(n_{i}\right)-p_{I O C_{\text {obtained }}}\left(n_{i}\right)
$$


Interpolating the data $\left(N_{i}, r c\left(N_{i}\right)\right) ; i=1,2, \ldots, 10$ to a polynomial of degree five, one gets a smooth function $\operatorname{rc}(N)$ obtained by Mathematica command SplineFit using option Cubic.

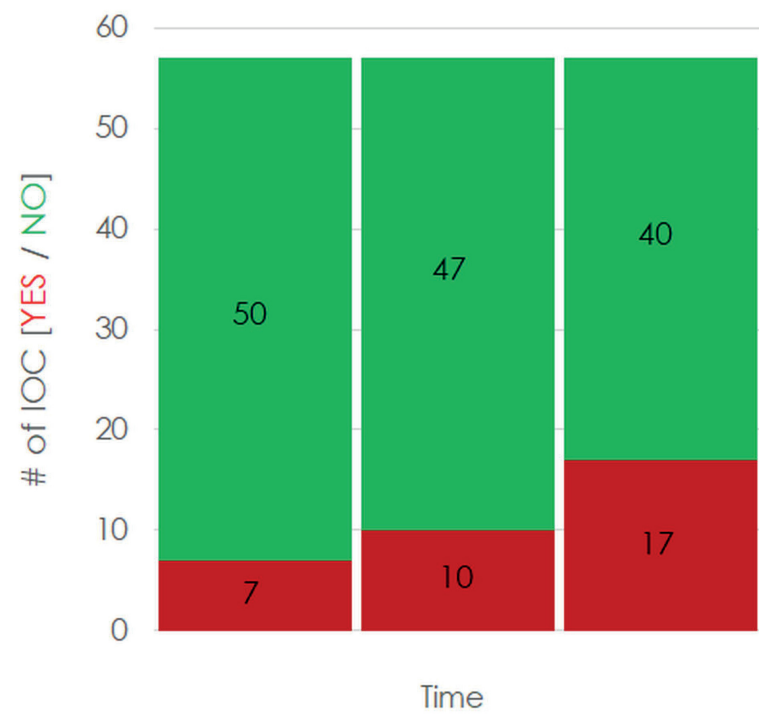

FIGURE 2. Histogramic time classes dependency of intraoperative complication (IOC) (yes/no) on the observed cohort.

TABLE 1. Baseline characteristics of 171 patients who underwent laparoscopic liver resection

\begin{tabular}{|c|c|}
\hline Baseline characteristics & $N^{a, b}$ \\
\hline Male sex & $104(60.8 \%)$ \\
\hline Age $\left(\right.$ years) ${ }^{\mathrm{b}}$ & $64(20-86,15)$ \\
\hline BMI $\left(\mathrm{kg} / \mathrm{m}^{2}\right)^{\mathrm{b}}$ & $27(18-50,4.8)$ \\
\hline ASA score ${ }^{a}$ & $\begin{array}{c}144(25.7 \%) \\
273(42.7 \%) \\
351(29.8 \%) \\
43(1.8 \%)\end{array}$ \\
\hline Liver cirrhosis Child-Pugh (22) ${ }^{a}$ & $\begin{array}{c}\text { A } 33(19.3 \%) \\
\text { B } 4(2.3 \%)\end{array}$ \\
\hline Previous abdominal surgerya & $41(24.0 \%)$ \\
\hline Previous liver resection ${ }^{a}$ & $8(4.6 \%)$ \\
\hline Malignant tumoura & $128(74.9 \%)$ \\
\hline Neoadjuvant chemotherapya & $25(14.6 \%)$ \\
\hline Max. diameter $(\mathrm{mm})^{\mathrm{b}}$ & $38(2-160,33)$ \\
\hline Number of tumoursa & $1(1-10,0)$. \\
\hline Deep location within liver ${ }^{a}$ & $50(29.2 \%)$ \\
\hline Posterosuperior liver segments ${ }^{a}$ & $49(28.7 \%)$ \\
\hline
\end{tabular}

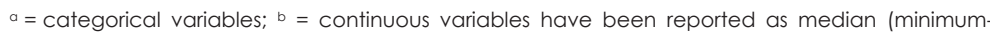
maximum, interquartile range); $\mathrm{ASA}=$ American Society of Anaesthesiologists; $\mathrm{BMI}=$ body mass index
Additionally, $r c=r c(N)$ was finally modified to relative complexity $(R C)$ for each sequential patient

$$
R C(n)=\operatorname{rc}\left(\frac{n+16}{17}\right)
$$

4. Adding both components, we get the learning curve $(L C)$ of the surgeon: $L C(n)=A C(n)+R C(n)$

\section{Results}

\section{The presentation of the cohort}

Between April 2008 and April 2021, 171 patients underwent pure LLR. Their baseline characteristics are presented in Table 1.

Perioperative outcomes are given in Table 2.

Two patients $(1.2 \%)$ suffered from unintentional laceration of the transverse colon, sutured laparoscopically. The procedure was completed laparoscopically in 147 (86.0\%) patients. The reasons for conversion to laparotomy in $24(14.0 \%)$ patients were diffuse parenchymal bleeding $(\mathrm{N}=3)$, inability to proceed due to the large liver or dense adhesions $(\mathrm{N}=6)$, and oncological concern $(\mathrm{N}=15)$. The decision to proceed to conversion was not made upon life-threatening bleeding. The indication for liver resection in converted cases was malignant tumours. Three $(1.8 \%)$ patients died - one bled out from ruptured oesophageal varices, and two died of liver failure; they all had hepatocellular carcinoma and liver cirrhosis Child-Pugh B.

\section{Learning curve analysis results}

The analysis of the learning curve was motivated by the increasing time dependency of HDS. Therefore, resections were divided into three sequential classes of 57 resections, and the number of obtained IOC in each class was counted. The results are graphically presented in Figure 2.

On $\alpha=5 \%$ significance level the $p$-value for Chi Square test is slightly above 5\% ( $p=0.055)$. However, for linear-by-linear (Mantel Haenszel) test for trend, the $\mathrm{p}$-value is $<0.05$.

HDS $^{10}$ was used in the analysis of LC. The riskof-IOC dependency was proven to be (on average) an increasing function in terms of HDS (Figure 1). A time-dependent and increasing trend can also be seen in Figure 3 (see the red linear trend-line for HDS; the blue chart represents actual data).

The sequential number of the patient corresponds to the effort of the surgeon (the correspondence is monotonically increasing). In the first class, 
the average time difference between sequential surgeries was 117 days (with a standard deviation of 132 days), while in the last class, the time difference was 13 days with a standard deviation of 12 days. The paired samples t-test shows that (at the level of confidence of $95 \%$ ) the two means are not equal $(p<0.05)$.

The final result of our LC data analysis is presented in Figure 4. Ten consecutive classes of 17 patients are given on abscissa. The height of the columns represents the share of the IOC in the time class. Two types of LCs for the observed cohort and the surgeon under consideration are given. The orange line represents the logarithmic regression curve based on absolute complexity for data $\left(N_{i}, a c\left(N_{i}\right)\right)$. The green line represents the sum of the orange curve and the quintic regression line of relative complexity for data $\left(N_{i}, r c\left(N_{i}\right)\right)$. This green line represents our LC.

\section{Discussion}

Like any other human activity, where individuals perform more difficult and intricated tasks over time, surgeons have been interested in their LC when performing LLR. ${ }^{16}$ The obtained learning curve has resulted from thirteen years of surgical effort of a single surgeon. It consists of an absolute and a relative part in the mathematical description of the additive function described by the logarithmic function (absolute complexity) and fifth-degree regression curve (relative complexity). The obtained LC determines the functional dependency of the learning outcome versus time and indicates several local extreme values (peaks and valleys) in the learning process until proficiency is achieved.

A typical LC graphically represents the relationship between the learning effort and achievement. LC consists of a measure of learning which usually lies on the ordinate (y-axis), a measure of effort, which usually lies on the abscissa ( $x$-axis) and a mathematical linking function. The shapes of this mathematical (functorial) dependence can vary depending on the nature and difficulty of the learning outcomes and difficulty of the task. ${ }^{26,27}$

It may be assumed that LC should be increasing in time (i.e., with effort). There are several typical LCs for learning different skills whose shape depends on the complexity of the task. When learning simple skills, S-shaped or logistic curves appear. The logistic curve admits a single inflexion point (indicating the point when half of the knowledge
TABLE 2. Perioperative outcomes of 171 patients who underwent laparoscopic liver resection

\begin{tabular}{|c|c|}
\hline Intraoperative details and postoperative course & $N^{a, b}$ \\
\hline Anatomic resection (23) a & $101(59.1 \%)$ \\
\hline Anatomically major resection (23) a & $27(15.8 \%)$ \\
\hline Technically major resection $(24)^{a}$ & $29(17.0 \%)$ \\
\hline Operation time $(\mathrm{min})^{\mathrm{b}}$ & $160(25-450,90)$ \\
\hline Blood loss $(\mathrm{mL})^{\mathrm{b}}$ & $150(0-2200,180)$ \\
\hline Intraoperative complication $(10)^{c}$ & 34 (19.9\%) \\
\hline Conversion to open approach ${ }^{a}$ & $24(14.0 \%)$ \\
\hline Blood loss $>775 \mathrm{~mL}^{\mathrm{a}}$ & $12(7.0 \%)$ \\
\hline Unintentional damage to the surrounding structures ${ }^{a}$ & $2(1.2 \%)$ \\
\hline Hepatic pedicle clamping ${ }^{a}$ & $45(26.3 \%)$ \\
\hline Total hepatic pedicle clamping time $(\mathrm{min})^{\mathrm{b}}$ & $8(0-75,10)$ \\
\hline Transfusion requireda & $20(11.7 \%)$ \\
\hline \multicolumn{2}{|l|}{ Pathohistological diagnosis } \\
\hline Colorectal liver metastases & $53(31 \%)$ \\
\hline Hepatocellular carcinoma & $46(29.6 \%)$ \\
\hline Intrahepatic cholangiocarcinoma & $14(8.2 \%)$ \\
\hline Other metastases & $11(6.4 \%)$ \\
\hline Hepatic cysts & $10(5.8 \%)$ \\
\hline Hepatic adenoma & $6(4.7 \%)$ \\
\hline Focal nodular hyperplasia & $8(4.7 \%)$ \\
\hline Haemangioma & $6(3.5 \%)$ \\
\hline Other pathology & $15(8.8 \%)$ \\
\hline RO resection & $163(95.3 \%)$ \\
\hline Major morbidity CD 3a-4b (25) & $21(12.3 \%)$ \\
\hline Hospital stay (days)b & $6(2-79,4)$ \\
\hline
\end{tabular}

$a=$ categorical variables; $b=$ continuous variables have been reported as median (minimummaximum, interquartile range); $c=$ intraoperative complication was defined as blood loss over $775 \mathrm{~mL}$, unintentional damage to the surrounding structures and conversion to open approach

was acquired) and a horizontal asymptote (representing the cap to be acquired). In surgical procedures for more complex skills, often a logarithmic LC without a cap appears. However, when interpreting a paediatric ankle radiograph, the LC turns out to be logarithmic. ${ }^{27}$ The zig-zag shape can appear as well. ${ }^{27} \mathrm{~A}$ steep $\mathrm{LC}$ is rare in medicine since the skills are associated with difficult and complex procedures. ${ }^{26,27}$

We have considered the LC of a single surgeon in a technically demanding LLR. When implementing a new surgical procedure, a surgeon already has some fundamental knowledge. The learning outcome is assumed to be proportional to the share of IOC made by the surgeon, i.e. we learn from our 


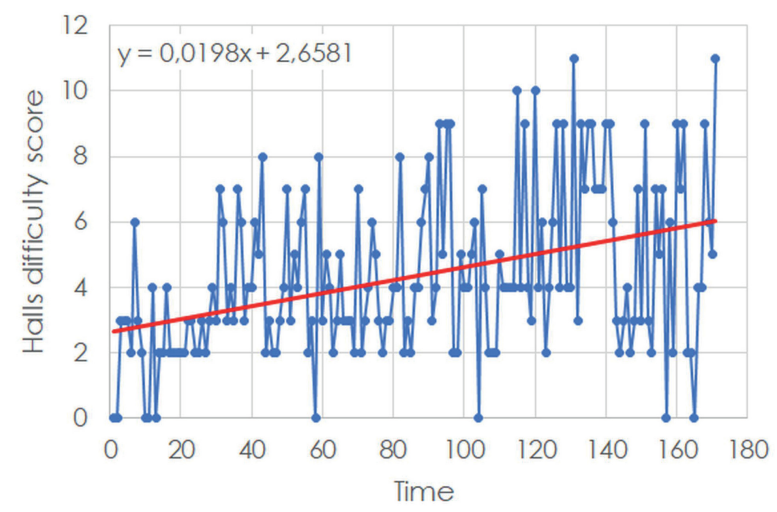

FIGURE 3. Time dependency of the Halls difficulty score on the observed cohort (blue points) and its regression (trend) line (red line).

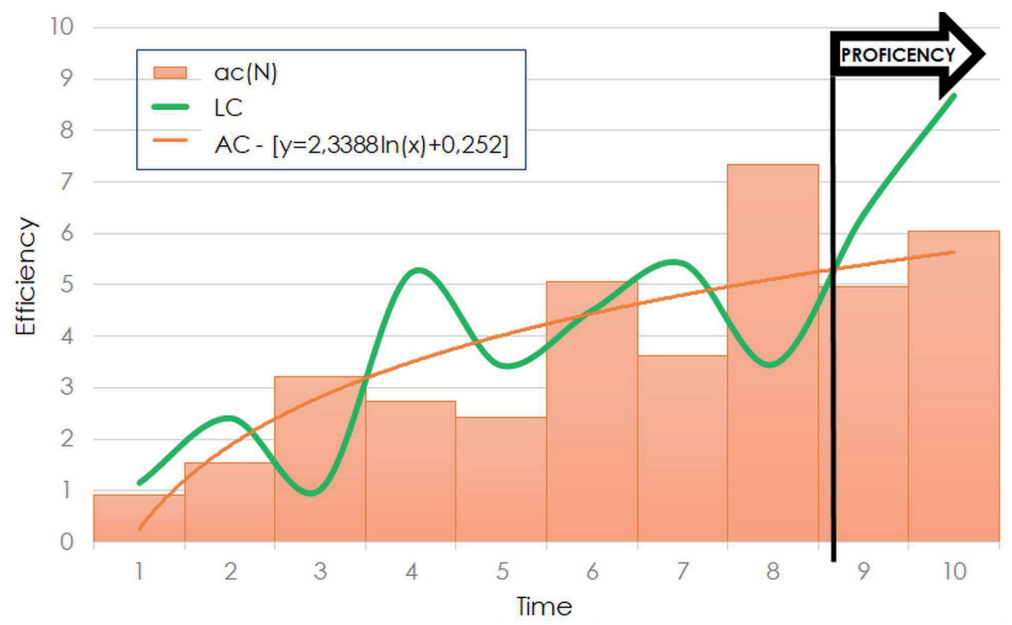

FIGURE 4. Two types of learning curves for observed cohort and the surgeon under consideration. The orange line $(\mathrm{AC})$ represents the logarithmic regression curve based on absolute complexity. The green line (LC) represents the sum of the orange curve and the quintic regression line of relative complexity. This line represents our learning curve.

$A C=$ absolute complexity; $a c(N)=$ absolute complexity expressed by the number of intraoperative complications; LC = learning curve

mistakes (IOC). However, LLR has not been a single procedure, and the complexity of operations varies from wedge resections to extended major hepatectomies. This fact contributes to the difficulties during learning and assessing the LC. ${ }^{12-16}$ In the beginning, solitary and peripherally located symptomatic benign tumours in anterolateral segments were resected. ${ }^{28}$ With growing experience, the laparoscopic approach was implemented regardless of tumour location and its characteristics. ${ }^{1,5}$ The time difference between sequential surgeries in time classes shortened from 117 days to 13 days. Therefore, one could reasonably assume this was a part of the learning strategy.
It is assumed that a higher level of (the sum of) theoretically predicted probability of IOC (within a particular class) reflects a higher level of gained knowledge (higher grade for the LC). This may be justified because the average HDS is also increasing with time (Figure 4). Therefore, HDS affects the relative complexity of the case. The orange line represents the basic LC. The relative complexity depends on the subjective decision made by the surgeon according to previously successfully finished cases with no IOC. LLR has been encompassing different procedures, each with its own anatomic and procedural considerations. Komatsu et al..$^{13}$ demonstrated an ideal learning curve effect for the left lateral sectionectomy and left hepatectomy, but it was not observed for the right hepatectomy. The more successive cases with no IOC encouraged the surgeon to do more cases with increased HDS.

When analysing IOC, the conversion rate of $14 \%$ was consistent with the reported ones, counting from $1 \%$ to $17 \%{ }^{15,29}$ An increased risk of conversion has been associated with neoadjuvant chemotherapy, previous open liver resection, malignant tumours, their size, anatomically major and technically major resection. ${ }^{30}$ Patients who had an elective conversion for an unfavourable intraoperative finding had better outcomes than patients who had an emergency conversion secondary to an adverse intraoperative event. ${ }^{30}$ All our converted cases occurred in malignant tumours. None of the cases was related to life-threatening bleeding. The most common indications for conversion were the inability to proceed and oncological concern, respectively. A chosen method does not change the principle of the surgery. Therefore, an oncologically uncompromised resection has been more crucial than the laparoscopic completion of the procedure. The overall major morbidity and mortality rates of $12.3 \%$ and $1.8 \%$ followed reports in the literature. ${ }^{13,14,16}$ To sum up, this conversion rate reflected the surgeon's reliance on the open method when dealing with adverse intraoperative findings. ${ }^{20}$

Although the first anatomical LLR was performed in $1996^{31}$, the first difficulty score was published not earlier than 2014. ${ }^{32}$ Our first LLR was performed in 2008, and the surgeon had to lean on his experience from open liver surgery. It would be riveting to study the results of the surgeon's trainees who could benefit from the evolution of techniques, learning modules ${ }^{12,16,33}$, and difficulty scores. ${ }^{6-8,10}$

The main shortcoming of the presented research is a relatively low number of patients. Therefore, in future research, a larger number of patients should 
be involved to show the robustness of the presented LC. Furthermore, its retrospective manner is another limitation.

The proposed LC and used methodology could guide the trainee surgeons and monitor their performance. In this sense, practitioners should be provided with a statistically independent set of patients with a constant increase (i.e., a constant gradient) of HDS over time. Thus, more difficult cases would be taken over by more qualified surgeons. A newly created application would randomly select patients with the appropriate HDS for each practitioner. It would enable control of the (accidental) variability in HDS and its consequences on IOC, which could not be completely avoided in practice. Under the supervision of a qualified operator, the objective evaluation of the LC would avoid deeper valleys in it (higher number of IOCs than theoretically expected) and thus ensure the most optimal learning. Given the basic assumption that we learn from our mistakes (see section A mathematical modelling of a learning curve), the maximal acceptable number and type of mistakes in the learning process should be objectively evaluated through further research.

To conclude, our LC is closer to a true model in which alternating periods of progression and regression occurred until mastery was achieved. ${ }^{16}$ Furthermore, the method presented in this paper can be applied to any (surgical) procedure with a difficulty score and given outcome (for example IOC), if a theoretically predicted probability dependence for the given outcome is available. From this point of view, the method is novel.

\section{Acknowledgement}

This work was supported by University Medical Centre Maribor (grant number IRP-2019/01-03). The funding source has no role in the design, practice, or analysis of this study.

\section{References}

1. Buell JF, Cherqui D, Geller DA, O'Rourke N, lannitti D, Dagher I, et al. The international position on laparoscopic liver surgery: The Louisville Statement, 2008. Ann Surg 2009; 250: 825-30. doi: 10.1097/sla.0b013e3181b3b2d8

2. Ciria R, Cherqui D, Geller DA, Briceno J, Wakabayashi G. Comparative shortterm benefits of laparoscopic liver resection: 9000 cases and climbing. Ann Surg 2016; 263: 761-77. doi: 10.1097/sla.0000000000001413

3. Wakabayashi G, Cherqui D, Geller DA, Buell JF, Kaneko H, Han HS, et al. Recommendations for laparoscopic liver resection: a report from the second international consensus conference held in Morioka. Ann Surg 2015; 261: 619-29. doi: 10.1097/sla.0000000000001184
4. Cherqui D, Wakabayashi G, Geller DA, Buell JF, Han HS, Soubrane O, et al. The need for organization of laparoscopic liver resection. J Hepatobiliary Pancreat Sci 2016; 23: 665-67. doi: 10.1002/jhbp.401

5. Abu Hilal M, Aldrighetti L, Dagher I, Edwin B, Troisi RI, Alikhanov R, et al. The Southampton consensus guidelines for laparoscopic liver surgery: from indication to implementation. Ann Surg 2018; 268: 11-8. doi: 10.1097/ sla.0000000000002524

6. Wakabayashi G. What has changed after the Morioka consensus conference 2014 on laparoscopic liver resection? Hepatobiliary Surg Nutr 2016; 5: 281 9. doi: 10.21037/hbsn.2016.03.03

7. Hasegawa $\mathrm{Y}$, Wakabayashi $\mathrm{G}$, Nitta $\mathrm{H}$, Takahara T, Katagiri $\mathrm{H}$, Umemura A, et al. A novel model for prediction of pure laparoscopic liver resection surgical difficulty. Surg Endosc 2017; 31: 5356-63. doi: 10.1007/s00464-017-5616-8

8. Kawaguchi Y, Fuks D, Kokudo N, Gayet B. Difficulty of laparoscopic liver resection: proposal for a new classification. Ann Surg 2018; 267: 13-7. doi: 10.1097/sla.0000000000002176

9. Hallet J, Pessaux P, Beyfuss KA, Jayaraman S, Serrano PE, Martel G, et al. Critical appraisal of predictive tools to assess the difficulty of laparoscopic liver resection: a systematic review. Surg Endosc 2019; 33: 366-76. doi: 10.1007/s00464-018-6479-3

10. Halls MC, Berardi G, Cipriani F, Barkhatov L, Lainas P, Harris S, et al Development and validation of a difficulty score to predict intraoperative complications during laparoscopic liver resection. Br J Surg 2018; 105: 1182 91. doi: 10.1002/bjs.1082

11. Ivanecz A, Plahuta I, Magdalenić T, Mencinger M, Peruš I, Potrč $S$, et al. The external validation of a difficulty scoring system for predicting the risk of intraoperative complications during laparoscopic liver resection. BMC Surg 2019; 19: 179. doi: 10.1186/s12893-019-0645-y

12. Guilbaud T, Birnbaum DJ, Berdah S, Farges O, Beyer Berjot L. Learning curve in laparoscopic liver resection, educational value of simulation and training programmes: a systematic review. World J Surg 2019; 43: 2710-9. doi: 10.1007/s00268-019-05111-x

13. Komatsu S, Scatton O, Goumard C, Sepulveda A, Brustia R, Perdigao F, et al. Development process and technical aspects of laparoscopic hepatectomy: learning curve based on 15 years of experience. J Am Coll Surg 2017; 224: 841-50. doi: 10.1016/j.jamcollsurg.2016.12.037

14. van der Poel MJ, Besselink MG, Cipriani F, Armstrong T, Takhar AS, van Dieren $S$, et al. Outcome and learning curve in 159 consecutive patients undergoing total laparoscopic hemihepatectomy. JAMA Surg 2016; 151: 923-28. doi: 10.1001/jamasurg.2016.1655

15. Vigano L, Laurent A, Tayar C, Tomatis M, Ponti A, Cherqui D. The learning curve in laparoscopic liver resection: improved feasibility and reproducibility. Ann Surg 2009; 250: 772-82. doi: 10.1097/SLA.0b013e3181bd93b2

16. Villani V, Bohnen JD, Torabi R, Sabbatino F, Chang DC, Ferrone CR "Idealized" vs. "True" learning curves: the case of laparoscopic liver resection. HPB (Oxford) 2016; 18: 504-9. doi: 10.1016/j.hpb.2016.03.610

17. Han HS, Cho JY, Yoon YS. Techniques for performing laparoscopic liver resection in various hepatic locations. J Hepatobiliary Pancreat Surg 2009; 16: 427-32. doi: 10.1007/s00534-009-0118-2

18. Ivanecz A, Krebs B, Stozer A, Jagric T, Plahuta I, Potrc S. Simultaneous pure laparoscopic resection of primary colorectal cancer and synchronous liver metastases: a single institution experience with propensity score matching analysis. Radiol Oncol 2018; 52: 42-53. doi: 10.1515/raon-2017-0047

19. Ivanecz A, Pivec V, llijevec B, Rudolf S, Potrč S. Laparoscopic anatomical liver resection after complex blunt liver trauma: a case report. Surg Case Rep 2018; 4: 25. doi: 10.1186/s40792-018-0432-5

20. Ivanecz A, Plahuta I, Magdalenić T, llijevec B, Mencinger M, Peruš I, et al. Evaluation of the Iwate model for predicting the difficulty of laparoscopic liver resection: does tumor size matter? J Gastrointest Surg 2021; 25: 1451 60. doi: 10.1007/s11605-020-04657-9

21. Weibull W. A statistical distribution function of wide applicability. J App Mech 1951; 18: 293-97.

22. Pugh RN, Murray-Lyon IM, Dawson JL, Pietroni MC, Williams R. Transection of the oesophagus for bleeding oesophageal varices. Br J Surg 1973; 60: 646-9. doi: 10.1002/bjs.1800600817

23. Strasberg SM, Belghiti J, Clavien PA, Gadzijev E, Garden JO, Lau WY, et al. The Brisbane 2000 terminology of liver anatomy and resections. HPB 2000; 2: 333-39. doi: 10.1016/S1365-182X(17)30755-4 
24. Kazaryan AM, Røsok BI, Marangos IP, Rosseland AR, Edwin B. Comparative evaluation of laparoscopic liver resection for posterosuperior and anterolateral segments. Surg Endosc 2011; 25: 3881-9. doi: 10.1007/s00464-011$1815-x$

25. Clavien PA, Barkun J, de Oliveira ML, Vauthey JN, Dindo D, Schulick RD, et al. The Clavien-Dindo classification of surgical complications: five-year experience. Ann Surg 2009; 250: 187-96. doi: 10.1097/SLA.0b013e3181b13ca2

26. Hopper AN, Jamison MH, Lewis WG. Learning curves in surgical practice. Postgrad Med J 2007; 83: 777-9. doi: 10.1136/pgmj.2007.057190

27. Pusic MV, Boutis K, Hatala R, Cook DA. Learning curves in health professions education. Acad Med 2015; 90: 1034-42. doi: 10.1097/ acm.0000000000000681

28. Nguyen KT, Gamblin TC, Geller DA. World review of laparoscopic liver resection-2,804 patients. Ann Surg 2009; 250: 831-41. doi: 10.1097/ SLA.0b013e3181b0c4df

29. Costi R, Scatton O, Haddad L, Randone B, Andraus W, Massault PP, et al. Lessons learned from the first 100 laparoscopic liver resections: not delaying conversion may allow reduced blood loss and operative time. J Laparoendosc Adv Surg Tech A 2012; 22: 425-31. doi: 10.1089/ lap.2011.0334

30. Halls MC, Cipriani F, Berardi G, Barkhatov L, Lainas P, Alzoubi M, et al. Conversion for unfavorable intraoperative events results in significantly worse outcomes during laparoscopic liver resection: lessons learned from a multicenter review of 2861 cases. Ann Surg 2018; 268: 1051-57. doi: $10.1097 /$ sla.0000000000002332

31. Azagra JS, Goergen M, Gilbart E, Jacobs D. Laparoscopic anatomical (hepatic) left lateral segmentectomy-technical aspects. Surg Endosc 1996; 10: 758-61. doi: 10.1007/bf00193052

32. Ban $\mathrm{D}$, Tanabe $\mathrm{M}$, Ito $\mathrm{H}$, Otsuka $\mathrm{Y}$, Nitta $\mathrm{H}$, Abe $\mathrm{Y}$, et al. A novel difficulty scoring system for laparoscopic liver resection. J Hepatobiliary Pancreat SC 2014; 21: 745-53. doi: 10.1002/jhbp.166

33. Goh BKP, Prieto M, Syn N, Koh YX, Lim KI. Critical appraisal of the learning curve of minimally invasive hepatectomy: experience with the first 200 cases of a Southeast Asian early adopter. ANZ J Surg 2020; 90: 1092-98. doi: 10.1111/ans.15683 